\title{
SENSITIVE ANALYSIS OF A COAL COMBUSTION MODEL ON A DROP TUBE FURNACE
}

\author{
L. Zimmer, \\ F. M. Pereira, \\ and P. S. Schneider \\ Universidade Federal do Rio Grande do Sul \\ Departamento de Engenharia Mecânica \\ Bairro Cidade Baixa \\ Porto Alegre, Rio Grande do Sul, Brasil \\ ABSTRACT \\ In the present work a one-dimensional model for coal combustion in a Drop \\ Tube Furnace (DTF) is developed. The equations that characterize the flow, \\ heat transfer phenomena and coal combustion reactions are programmed in \\ a FORTRAN90 language code. The results are compared with a reference \\ model and experimental data, showing good agreement. A sensitivity study \\ is performed to understand the behavior of coal combustion due to changes \\ of some working parameters of the DTF. From the variation of the oxygen \\ concentration, working temperature and input flow rates the response of the \\ coal combustion in terms of unburned fraction can be obtained.
}

CEP. 90050-170

leo.zimmer@mecanica.ufrgs.br

Received: November 18, 2013

Revised: November 22, 2013

Accepted: December 30, 2013

Keywords: Drop Tube Furnace, coal combustion, sensitivity analysis.

\section{NOMENCLATURE}

A pre-exponential factor, different units

A ash content, $\mathrm{kg}$ of ash $/ \mathrm{kg}$ of particles

C char content, $\mathrm{kg}$ of char $/ \mathrm{kg}$ of particles

$\mathrm{c}_{\mathrm{p}} \quad$ fluid specific heat at constant pressure, $\mathrm{J} /(\mathrm{kg} . \mathrm{K})$

d diameter, $\mathrm{m}$

$\mathrm{D}_{\mathrm{O} 2}{ }^{\mathrm{M}} \quad \mathrm{O}_{2}$ diffusivity coefficient into the mixture, $\mathrm{m}^{2} / \mathrm{s}$

E activation energy, $\mathrm{J} / \mathrm{mol}$

$\mathrm{H}$ moisture content, $\mathrm{kg}$ of moisture $/ \mathrm{kg}$ of particles

$\mathrm{H}_{\mathrm{C}} \quad$ combustion enthalpy, $\mathrm{J} / \mathrm{kg}$

$\mathrm{H}_{\mathrm{V}}$ devolatilisation enthalpy, $\mathrm{J} / \mathrm{kg}$

$\mathrm{k}$ constant rate, $1 / \mathrm{s}$

$\mathrm{k}_{\mathrm{C}} \quad$ constant rate of char oxidation, $\mathrm{kg} / \mathrm{m}^{2} . \mathrm{s}$

$\mathrm{m}$ mass, $\mathrm{kg}$

m mass flow, $\mathrm{kg} / \mathrm{s}$

M molar mass, $\mathrm{kg} / \mathrm{kmol}$

$\mathrm{Nu} \quad$ Nusselt number based on particle diameter

$\mathrm{p}$ pressure, $\mathrm{Pa}$

$\mathrm{Q}_{\mathrm{v}}$ devolatilisation heat, $\mathrm{W}$

$\mathrm{Q}_{\mathrm{C}}$ heat of combustion of fixed carbon, W

$\mathrm{Q}_{\text {conv }}$ heat exchange by convection, W

$\mathrm{Q}_{\mathrm{rad}}$ radiate heat exchange, $\mathrm{W}$

$\mathrm{r}_{\mathrm{s}} \quad$ particle radius, $\mathrm{m}$

$\mathrm{R}_{\mathrm{kin}} \quad$ kinetic resistance, $\mathrm{s} / \mathrm{kg}$

$\mathrm{R}_{\text {dif }}$ diffusion resistance, $\mathrm{s} / \mathrm{kg}$

$\mathrm{Re} \quad$ Reynolds number based on particle diameter and relative velocity

$\mathrm{Ru}$ universal gas constant, $\mathrm{J} / \mathrm{mol} . \mathrm{K}$

t time, $s$

$\mathrm{T}$ temperature, $\mathrm{K}$

u velocity, $\mathrm{m} / \mathrm{s}$
U coal unburnt fraction

$\mathrm{V} \quad$ volatiles content, $\mathrm{kg}$ of devolatilisable

matter $/ \mathrm{kg}$ of particles

$\dot{\text { W }}$ source term, $\mathrm{kg} / \mathrm{m}^{3} . \mathrm{s}$

$\mathrm{y}$ mass fraction

\section{Greek symbols}

$\alpha \quad$ particle shrinking parameter

$\beta \quad$ particle shrinking parameter

$\varepsilon \quad$ emissivity of the particle

$\lambda$ thermal conductivity, $\mathrm{W} / \mathrm{m} . \mathrm{K}$

$\sigma \quad$ Stefan-Boltzmann constant, $\mathrm{W} / \mathrm{m}^{2} . \mathrm{K}^{4}$

$\rho$ density, $\mathrm{kg} / \mathrm{m}^{3}$

\section{Subscripts}

A ash

C char

$\mathrm{db}$ dry base

g gas

$\mathrm{H}$ moisture

j specie

$\mathrm{k}$ reaction

mixt mixture

$\mathrm{O}_{2} \quad$ oxygen

$\mathrm{p}$ particle

s particle surface

$\mathrm{v} \quad$ volatile

w wall

\section{Superscripts}

0 initial value 


\section{INTRODUCTION}

Coal remains the most abundant fossil fuel on earth and accounts for most of the production of electricity of several countries, according to CGEE (2012), and will continue to play an important role in world energy supply for many decades. According to BP (2012) coal consumption grew 5.4\% in 2011 and was the only fossil fuel to register above average growth. It also was the form of energy that has been rapidly growing, despite renewable energy. In addition, the coal in 2011 was responsible for $30.3 \%$ of global energy consumption, the highest share since 1969.

Considering the global energy participation, the petroleum had greater participation in global primary energy supply, with $33.2 \%$, by the year 2008, according to EPE (2011), followed by coal with $27 \%$. For the global supply of electricity, coal had the greatest participation, with $41 \%$, followed natural gas, with $21.3 \%$, for the same period.

However, in Brazil the primary energy supply, in 2010, was distributed among the non-renewable sources, with $53 \%$, which coals is included with $0.9 \%$, and renewable sources, with approximately $47 \%$, according to EPE (2011). In terms of electricity supply, the hydropower generation accounted for $74 \%$, while coal accounted only for $1 \%$, for the same period. Nonetheless coal use in Brazil for power generation grew $28.3 \%$ in 2011 , in respect to the previous year. National coal is produced in the states of Paraná, Santa Catarina and Rio Grande do Sul, and it is essentially, $80 \%$, used to power generation, CGEE (2012).

To understand more about the combustion of national coal, its efficiency and how to optimize it, it is necessary an extensive study of coal combustion, in addition to bench tests and facility tests. One useful experiment is the Drop Tube Furnace (DTF), which is able to create an environment that simulates similar conditions to those encounters in industrial burner, such as short residence time, high temperatures and high heating rates, Ulloa et al. (2005). Therefore, DTF is used to pyrolysis char and/or for coal reactivity analysis. From the knowledge of the phenomena, which govern the combustion within a DTF, it is possible, through numerical modeling and experimental data, to obtain the chemical kinetics parameters, Ballester and Jimenez (2005).

The main objective of this work is the study of burning coal in a DTF. From the literature, onedimensional DTF model is built, focusing on chemical reaction processes of coal combustion. The developed model is compared to a model adopted as the reference and to experimental data. Also, a sensitivity study of the model is done to understand the behavior of the system due to changes of some working parameters.

\section{DROP TUBE FURNACE}

The problem to be addressed in this work is the combustion of coal along a DTF reactor. The formulation of the problem is detailed for the specific case simulated, followed by models of heat transfer of the burning coal. The modeling used in this work aims to reproduce the experiments conducted in a DTF by Ballester and Jimenez (2005). This DTF is heated by heating elements (electrical resistances) and by flue gas from natural gas burner. The furnace reactor is a $\mathrm{SiC}$ tube, with $78 \mathrm{~mm}$ of internal diameter and $1.6 \mathrm{~m}$ long, and it can be operated up to $1773 \mathrm{~K}$. The pulverized fuel is injected through the top of the tube with the transport fluid (air) together with the co-flowing gases. The co-flowing gases consist of combustion products of natural gas from a primary combustor. The oxygen concentration at the entrance of the furnace can be controlled either by adjusting the flow rate of combustion air and transport fluid or by injecting pure oxygen. The operational conditions used in the simulation of the present work are presented in Tab. 1.

Table 1. Working condition of the DTF, adapted from Ballester and Jimenez (2005).

\begin{tabular}{cccccc}
\hline $\begin{array}{c}\text { Reactor } \\
\text { temperature (K) }\end{array}$ & 1313 & 1448 & 1573 & 1723 & 1573 \\
$\mathrm{CH}_{4}$ flow (1/h) & 70 & 70 & 70 & 70 & 70 \\
$\begin{array}{c}\text { Air flow for } \\
\text { burn } \mathrm{CH}_{4}(\mathrm{l} / \mathrm{h})\end{array}$ & 800 & 800 & 800 & 800 & 770 \\
$\begin{array}{c}\text { Transport fluid } \\
\text { (air) flow (1/h) }\end{array}$ & 250 & 250 & 250 & 250 & 250 \\
$\begin{array}{c}\mathrm{O}_{2} \text { flow added } \\
(\mathrm{l} / \mathrm{h})\end{array}$ & 0 & 0 & 0 & 0 & 43 \\
\hline
\end{tabular}

The present work uses the same coal as the reference work, anthracite coal, characterized by proximate analysis (by weight) as: $69.09 \%$ of Fixed Carbon, $\mathrm{C}^{0} ; 10.28 \%$ of Volatiles, $\mathrm{V}^{0} ; 19.17 \%$ of Ash, $\mathrm{A}^{0}$ and $1.46 \%$ of Moisture, $\mathrm{H}^{0}$; by ultimate analysis (by weight) as: $70.3 \%$ of $\mathrm{C} ; 3.03 \%$ of $\mathrm{H} ; 1.63 \%$ of $\mathrm{N} ; 2.28 \%$ of $\mathrm{S}$; and its $\mathrm{HHV}$ is $27.59(\mathrm{MJ} / \mathrm{kg})$. The particle diameters for all simulations were $52.2 \mu \mathrm{m}$ and were feeding at the rate of $30 \mathrm{~g} / \mathrm{h}$.

Ballester and Jimenez (2005) found different kinetic parameters for different modes of shrinking core of the particle, $\alpha$. The shrinking core model is presented in the next section. For $\alpha=0 \mathrm{~A}_{\mathrm{C}}$ is $4.00 \times 10^{-4}$ $\left(\mathrm{kg} / \mathrm{m}^{2} . \mathrm{s} . \mathrm{Pa}\right)$ and $\mathrm{E}_{\mathrm{C}}$ is $8.30 \times 10^{4}(\mathrm{~J} / \mathrm{mol})$; for $\alpha=0.08$ $\mathrm{A}_{\mathrm{C}}$ is $5.60 \times 10^{-4}\left(\mathrm{~kg} / \mathrm{m}^{2} . \mathrm{s} . \mathrm{Pa}\right)$ and $\mathrm{E}_{\mathrm{C}}$ is $8.60 \times 10^{4}$ $(\mathrm{J} / \mathrm{mol})$; and for $\alpha=0.33 \mathrm{~A}_{\mathrm{C}}$ is $1.49 \times 10^{-3}\left(\mathrm{~kg} / \mathrm{m}^{2} . \mathrm{s} . \mathrm{Pa}\right)$ and $E_{C}$ is $9.42 \times 10^{4}(\mathrm{~J} / \mathrm{mol})$. The value of $\alpha=0.08$ is the best fit found by the reference to represent the reduction of particle size and density for a multiple size coal population. These kinetic parameters of coal burning are used in the present work.

The combustion monitoring is based on the unburned fraction, $\mathrm{U}$, and it is calculated from the proximate analysis of fuel and char samples, according to the ash-as-tracer method from Ballester 
and Jimenez (2005). The relation to the model parameters is presented in the next section.

\section{COMBUSTION MODEL}

Thereby, for the present work it is assumed these simplification hypotheses: One-dimensional uniform flow and steady-state regime; Are neglected: thermal and mass diffusion in gas phase, gravity effect, particle interaction, viscous dissipation, and gas phase radiation; Coal particles are composed by fixed carbon, volatile, moisture and ash; Ash is an inert component and remains in the particle; The only product of devolatilisation is methane, $\mathrm{CH}_{4}$, which is instantaneously burnt; Coal particles have sphere format; Char reaction is a one-step reaction $\mathrm{CO}$ formation only, and is represented as $\mathrm{C}+1 / 2 \mathrm{O}_{2} \rightarrow$ $\mathrm{CO}$, which is instantaneously burnt; Initial particle diameter is just one; Atmospheric pressure in all domain and air is defined as dry-air; All fluids are modelled as perfect gases; Temperature particle is assumed be uniform within the particle; Particles are dragged by the flow and take its velocity; The drying process of the coal particle occurs immediate, due to the small quantity of moisture in the coal and the high heating rate of the reactor $\left(\sim 10^{4} \mathrm{~K} / \mathrm{s}\right)$; The particle is global modelled, without internal gradient of temperatures and concentration.

\section{Governing Equations}

According to Smoot and Smith (1985), Williams et al. (2000) and Glassman (2008), the devolatilisation process can be represented by a first order single step reaction, following an Arrhenius rate. The rate of mass loss of devolatilisable matter $\mathrm{dV} / \mathrm{dt}$ can be described as:

$$
\begin{gathered}
\frac{d V}{d t}=-k_{V} V \\
k_{v}=A_{v} \exp \left(E_{v} / \operatorname{RuT}_{p}\right)
\end{gathered}
$$

where $\mathrm{k}_{\mathrm{v}}$ is the devolatilisation constant rate, $1 / \mathrm{s} ; \mathrm{A}_{\mathrm{v}}$ is the pre-exponential factor, $1 / \mathrm{s} ; \mathrm{E}_{\mathrm{v}}$ is the activation energy for devolatilisation, $\mathrm{J} \mathrm{mol}{ }^{-1} ; \mathrm{Ru}$ is the universal gas constant, $\mathrm{J} / \mathrm{mol} . \mathrm{K} ; \mathrm{T}_{\mathrm{p}}$ is the temperature of the particle, $\mathrm{K}$, and $\mathrm{V}$ is the volatiles content, $\mathrm{kg}$ of devolatilisable matter $/ \mathrm{kg}$ of particles. Based on the work of Ballester and Jimenez (2005) the preexponential factor used is $6 \times 10^{5}, 1 / \mathrm{s}$, and the activation energy for devolatilisation is $144 \times 10^{3}$, $\mathrm{J} / \mathrm{mol}$.

The carbon reaction is modeled by an apparent kinetics, applied to the outer surface of the particle, which can be found in Turns (2000) and Coelho and Costa (2007). This model was then adapted to the main kinetic parameters used by Ballester and
Jimenez (2005), and the rate of consumption of carbon can be showed as:

$$
\begin{gathered}
\frac{\mathrm{dC}}{\mathrm{dx}}=-\left(\frac{\mathrm{y}_{\mathrm{O}_{2}}}{\mathrm{R}_{\mathrm{kin}}+\mathrm{R}_{\mathrm{dif}}}\right) \frac{\mathrm{N}_{\mathrm{p}}}{\mathrm{u}_{\mathrm{p}}} \\
\mathrm{R}_{\mathrm{kin}}=\frac{\mathrm{M}_{\mathrm{O}_{2}}}{4 \pi \mathrm{r}_{\mathrm{s}}^{2} \mathrm{k}_{\mathrm{C}} \mathrm{M}_{\text {mixt }} \mathrm{p}} \\
\mathrm{k}_{\mathrm{C}}=\mathrm{A}_{\mathrm{C}} \exp \left(\frac{-\mathrm{E}_{\mathrm{C}}}{\mathrm{RuT}_{\mathrm{p}}}\right) \\
\mathrm{R}_{\mathrm{dif}}=\frac{\mathrm{S}_{\mathrm{O}_{2}, \mathrm{CO}}+\mathrm{y}_{\mathrm{O}_{2}, \mathrm{~s}}}{4 \pi \mathrm{r}_{\mathrm{s}} \rho_{\mathrm{g}} \mathrm{D}_{\mathrm{O}_{2}}^{\mathrm{M}}} \\
\mathrm{N}_{\mathrm{p}}=\left(\frac{1}{6} \pi\left(\mathrm{d}_{\mathrm{p}}^{0}\right)^{3} \rho_{\mathrm{p}}^{0}\right)^{-1}
\end{gathered}
$$

where, $\mathrm{C}$ is the char content, $\mathrm{kg}$ of char $/ \mathrm{kg}$ of particles; $\mathrm{y}_{\mathrm{O} 2}$ the mass fraction of $\mathrm{O}_{2}$ in the ambient; $\mathrm{N}_{\mathrm{p}}$ the number of coal particles $/ \mathrm{kg}$ of coal, $1 / \mathrm{kg} ; \mathrm{u}_{\mathrm{p}}$ the velocity of the particle, $\mathrm{m} / \mathrm{s} ; \mathrm{R}_{\text {kin }}$ and $\mathrm{R}_{\text {dif }}$ are the kinetic and diffusion resistances, $\mathrm{s} / \mathrm{kg}$, respectively; $\mathrm{M}_{\mathrm{O} 2}$ the molar mass of $\mathrm{O}_{2}, \mathrm{~kg} / \mathrm{kmol} ; \mathrm{r}_{\mathrm{s}}$ the particle radius, $\mathrm{m} ; \mathrm{k}_{\mathrm{C}}$ the constant rate of char oxidation, $\mathrm{kg} / \mathrm{m}^{2} \mathrm{~s} ; M_{\text {mixt }}$ is the molar mass of the mixture, $\mathrm{kg} / \mathrm{kmol} ; \mathrm{p}$ is the pressure, $\mathrm{Pa} ; \mathrm{A}_{\mathrm{C}}$ is the preexponential factor of char oxidation, $\mathrm{kg} / \mathrm{m}^{2} . \mathrm{s} . \mathrm{Pa} ; \mathrm{E}_{\mathrm{C}}$ is the activation energy, $\mathrm{J} / \mathrm{mol} ; \mathrm{S}_{\mathrm{O} 2, \mathrm{CO}}$ the ratio of $\mathrm{O}_{2}$ mass per $\mathrm{C}$ mass to form $\mathrm{CO}$; $\mathrm{y}_{\mathrm{O} 2, \mathrm{~s}}$ the mass fraction of $\mathrm{O}_{2}$ on the surface of the coal particle; $\rho_{\mathrm{g}}$ the gas density, $\mathrm{kg} / \mathrm{m}^{3} ; \mathrm{D}_{\mathrm{O} 2}{ }^{\mathrm{M}}$ the $\mathrm{O}_{2}$ diffusivity coefficient into the mixture, $\mathrm{m}^{2} / \mathrm{s} ; \mathrm{d}_{\mathrm{p}}^{0}$ and $\rho_{\mathrm{p}}^{0}$ the initial particle diameter, $\mathrm{m}$, and density, $\mathrm{kg} / \mathrm{m}^{3}$, respectively.

Analyzing the change in mass fraction of carbon Eq. (3), together with the variation of mass fraction of volatile, Eq. (1), and knowing the mass of a particle is composed of mass fractions of carbon, volatile, ash and moisture, an expression for the mass flow rate of particles, $\mathrm{m}_{\mathrm{p}}$, can be obtained such as:

$$
\mathrm{m}_{\mathrm{p}}=\frac{\left(\mathrm{m}_{\mathrm{A}}+\mathrm{m}_{\mathrm{H}}\right)}{(1-(\mathrm{C}+\mathrm{V}))}
$$

where, $\mathrm{m}_{\mathrm{p}}, \mathrm{m}_{\mathrm{A}}$ and $\mathrm{m}_{\mathrm{H}}$ are mass of particles, ashes, and moisture, respectively, in $\mathrm{kg}$.

From Eq. (8) and definition of mass fractions of carbon and volatile is possible to obtain the carbon and volatile reaction rates in weight basis, $\mathrm{kg} / \mathrm{s}$, as follows:

$$
\dot{\mathrm{w}}_{\mathrm{C}}=\frac{\mathrm{dm}_{\mathrm{C}}}{\mathrm{dt}}
$$




$$
\dot{\mathrm{w}}_{\mathrm{V}}=\frac{\mathrm{dm}_{\mathrm{v}}}{\mathrm{dt}}
$$

Auxiliary equations:

The unburnt fraction, $\mathrm{U}$, is a dimensionless measure of the quantity of material which can react, and is calculated as:

$$
\mathrm{U}=\frac{\mathrm{C}+\mathrm{V}}{\mathrm{C}^{0}+\mathrm{V}^{0}}
$$

where $\mathrm{C}$ and $\mathrm{V}$ are mass fractions of fixed carbon and volatile matter, respectively. The superscript 0 means that the variable value is taken at the point of injection.

The model of reduced particle size is based on studies of Smith (1971a and 1971b), which proposed a relation to the evolution of the diameter and density of the carbon particle over time in relation to the burnt mass fraction of the particle. The relation can be written as function of unburnt fraction, $U$, as:

$$
\left(d_{p}\right)^{3} \rho_{p}=\left(d_{p}^{0}\right)^{3} \rho_{p}^{0} U
$$

Introducing the relation $3 \alpha+\beta=1$, the diameter and the particle density at any point can be found as:

$$
\begin{aligned}
& d_{p}=d_{p}^{0} U^{\alpha} \\
& \rho_{p}=\rho_{p}^{0} U^{\beta}
\end{aligned}
$$

Depending on the particle shrinking mode, it is possible to use the parameters $\alpha$ and $\beta$ for classifying the reduction model in a model of the particle constant diameter $(\alpha=0)$, of constant density $(\alpha=$ $1 / 3)$ or intermediate $(0<\alpha<1 / 3)$.

Gas phase equations:

The reactions taking place in homogeneous gaseous phase occur instantaneously as $\mathrm{CO}$ and $\mathrm{CH}_{4}$ are produced and are represented as:

$$
\begin{gathered}
\mathrm{CO}+1 / 2 \mathrm{O}_{2} \rightarrow \mathrm{CO}_{2} \\
\mathrm{CH}_{4}+2 \mathrm{O}_{2} \rightarrow \mathrm{CO}_{2}+2 \mathrm{H}_{2} \mathrm{O}
\end{gathered}
$$

Conservation of mass species:

$$
\frac{\mathrm{d}\left(\text { puy }_{\mathrm{j}}\right)}{\mathrm{dx}}=\sum_{\mathrm{j}, \mathrm{k}} \dot{\mathrm{W}}_{\mathrm{j}, \mathrm{k}}
$$

where $u$ is the flow velocity, $\mathrm{m} / \mathrm{s} ; \mathrm{y}_{\mathrm{j}}$ mass fraction of the specie $\mathrm{j} ; \dot{\mathrm{W}}_{\mathrm{j}, \mathrm{k}}$ the source term, $\mathrm{kg} / \mathrm{m}^{3} . \mathrm{s}$; which subscripts $\mathrm{j}$ and $\mathrm{k}$ represent the specie and the reaction, respectively.

Energy Equation:

The energy equation for a particle can be written as:

$$
\rho_{\mathrm{p}} \frac{1}{6} \pi \mathrm{d}_{\mathrm{p}}^{3} \mathrm{c}_{\mathrm{p}} \frac{\mathrm{dT}_{\mathrm{p}}}{\mathrm{dx}}=\frac{1}{\mathrm{u}}\left(\mathrm{Q}_{\mathrm{v}}+\mathrm{Q}_{\mathrm{C}}+\mathrm{Q}_{\mathrm{conv}}+\mathrm{Q}_{\mathrm{rad}}\right)
$$

where $c_{p}$ is the specific heat of the particle at constant pressure, kJ/kg.K; $\mathrm{Q}_{\mathrm{v}}, \mathrm{Q}_{\mathrm{C}}, \mathrm{Q}_{\text {conv }}$ and $\mathrm{Q}_{\mathrm{rad}}$ represent devolatilisation heat, the heat of combustion of fixed carbon, the heat exchange by convection and radiate heat exchange, respectively, in W. The density of the particles of coal is obtained from literature data, the value used in this study was $1500 \mathrm{~kg} / \mathrm{m}^{3}$, obtained from Basu (2006). The specific heat at constant pressure of the particle adopted is $1000 \mathrm{~kJ} / \mathrm{kg} . \mathrm{K}$, and was obtained from Tomeczek and Palugniok (1996).

The heat transferred between the gas and particle through convection can be described as:

$$
\mathrm{Q}_{\text {conv }}=\pi \mathrm{d}_{\mathrm{p}} \mathrm{Nu} \lambda_{\mathrm{g}}\left(\mathrm{T}_{\mathrm{g}}-\mathrm{T}_{\mathrm{p}}\right)
$$

where $\mathrm{Nu}$ is Nusselt number based on particle diameter; $\mathrm{T}_{\mathrm{g}}$ is gas temperature, $\mathrm{K}$, and $\lambda_{\mathrm{g}}$ is the thermal conductivity of the gas, W/m.K. As stated earlier, the relative velocity of the particle in relation to the gas flow velocity is zero, so Re is zero and $\mathrm{Nu}$ is considered equal to 2.0 as Basu (2006).

The heat exchange by radiation only occurs between the particles and the walls of the reactor. Whereas the size of each particle is much less than the diameter and tube length, it can be said that the form factor of each particle in relation to the reactor is equal to one. Thus, the heat transfer between the wall of the reactor and the particle through radiation can be described as:

$$
\mathrm{Q}_{\mathrm{rad}}=\pi \mathrm{d}_{\mathrm{p}}^{2} \varepsilon \sigma\left(\mathrm{T}_{\mathrm{w}}^{4}-\mathrm{T}_{\mathrm{p}}^{4}\right)
$$

where $\varepsilon$ is the emissivity of the particle, $\sigma$ is the Stefan-Boltzmann constant, and $\mathrm{T}_{\mathrm{w}}$ is the wall temperature, $\mathrm{K}$.

The heat release in the combustion and the heat to the endothermic process of devolatizition can be written as:

$$
\begin{aligned}
& \mathrm{Q}_{\mathrm{C}}=\frac{1}{\mathrm{~N}_{\mathrm{P}}} \frac{\mathrm{dC}}{\mathrm{dt}} \mathrm{H}_{\mathrm{C}} \\
& \mathrm{Q}_{\mathrm{V}}=\frac{1}{\mathrm{~N}_{\mathrm{P}}} \frac{\mathrm{dV}}{\mathrm{dt}} \mathrm{H}_{\mathrm{V}}
\end{aligned}
$$

where $H_{C}$ is the combustion enthalpy and $H_{V}$ the devolatilisation enthalpy, $\mathrm{J} / \mathrm{kg}$. 
All properties are calculated from the literature. The thermal conductivity of the gas according to Poling et al. (2000), the oxygen diffusivity into the gases and viscosity are calculated through ChapmanEnskog equation.

\section{NUMERICAL METHOD}

It is applied the finite volume numerical method for solving partial differential equations. The problem is parabolic and so is treated as convective-dominant and the interpolation scheme for convective terms is upwind scheme. The solution of the problem takes place in a marching procedure, where the next volume is only achieved when all variables converged. The convergence criteria used was $10^{-6}$ for all variables, and to achieve this criteria the mesh was refined until 70 thousand volumes. The program was written in Fortran 90 programming language using the Gfortran compiler (gcc-4.6.0) with all values expressed in double precision. The duration of each simulation was approximately 70 seconds in a MacBook Pro with Core 2 Duo $2.4 \mathrm{GHz}$ processor and 8 GB of RAM.

\section{RESULTS}

The experiment from Ballester and Jimenez (2005) is chosen to compare the results, which from now on is called the reference experiment, for simplicity. Table 1 shows the operation data of the experiment of reference, and from these data, it is calculated the mass flow rates of the species of the gases of the process necessary to feed the numerical model.

\section{Comparison with the reference work:}

This section will compare the results of this model with those presented by the reference work for the same operating conditions of the reactor DTF. The main differences are: The reference model assumes a relative velocity of the particle with respect to gas flow, while in the present work the particle velocity is the same flow; The present model has a more detailed model of the diffusion of oxygen; The thermo-physical properties in the current model are calculated for each point in the reactor, while in the reference model are considered constant; For some situations, the reference work employs a sample with variable particle size, while in this study it is considered as fixed size of $52.2 \mu \mathrm{m}$ diameter; Additionally, the reference work obtained the kinetic parameters of the coal reaction by setting their model with experimental data. Therefore, these parameters can be very sensitive to the adopted model and its assumptions.

The first comparisons between models were at temperatures of $1573 \mathrm{~K}$ and $1723 \mathrm{~K}$. Also it was considered three values of $\alpha$ for the model to reduce the particle size, $\alpha=0,0.08$ and 0.33 . The model showed the same trends in unburnt fraction $U$ for the three models of reduction of particle size. However, the values found had a certain deviation from the reference model, as the reference model had a higher conversion of char than the present model for all values of $\alpha$. The differences were due to the models adopted, the simplifying assumptions and also to the fact that the kinetic parameters used in this work were obtained particularly for the reference model. The best fit to experimental data was using $\alpha$ equal to $1 / 3$, meaning that the constant density-shrinking model reduced the differences between the present model and the experimental data. From this statement, the second analysis is made comparing the present model, taking account $\alpha$ equal to $1 / 3$, over different working conditions, shown in the Tab.1. The results presented similar values compared to the reference model, with slightly deviations due to different modeling methods. To avoid confusion it is only shown the comparison of the simulation results of the present work with the reference experiments, shown in Fig. 1.

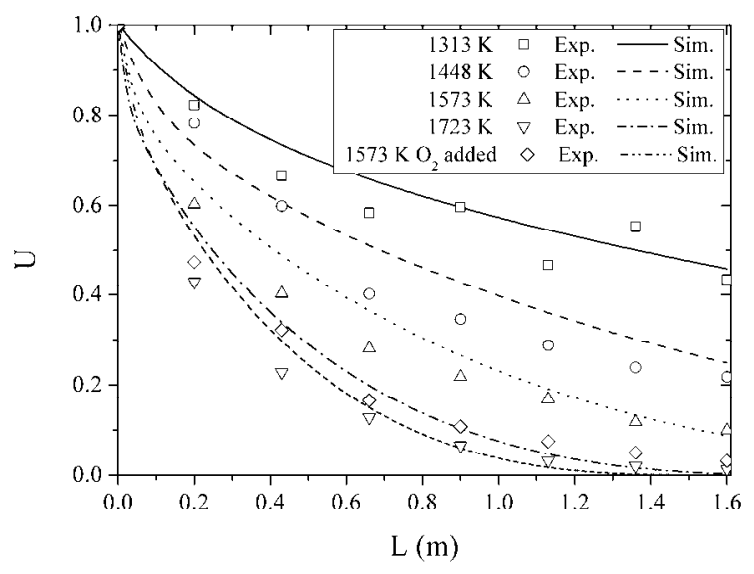

Figure 1. Values of unburnt fraction $U$ along the reactor for various temperatures; Comparative between experimental values of Ballester e Jimenez (2005) and the present simulation, for $\alpha=1 / 3$ and $\mathrm{d}_{\mathrm{p}}=52.2 \mu \mathrm{m}$.

From Fig. 1 it can be noticed that while the present model uses a different shrinking model $(\alpha=0.33)$ and mono size particles, the results have the same tendency of the experimental data, which considered multiple size particles. It is also interesting to note that the results for the case of 1723 $\mathrm{K}$ and $1573 \mathrm{~K}$ with the addition of $\mathrm{O}_{2}$ are similar. The higher $\mathrm{O}_{2}$ concentration has the same effect in the global reactivity as increasing the reactor temperature.

\section{Sensitivity analysis}

Sensitivity analysis seeks to determine the effect on the system when one of its parameters is changed, while keeping the others constant. Here it is 
presented the main parameters which had most effect on the system. The nominal values are based on the values of the experiment running at $1723 \mathrm{~K}$.

$\mathrm{O}_{2}$ concentration:

The nominal value of $8 \%$ of the $\mathrm{O}_{2}$ molar fraction on a dry basis is taken as reference, and is obtained with the $\mathrm{CH}_{4}$ flow rate of $70.69 \mathrm{l} / \mathrm{h}$ and with air flow rate of $799.61 \mathrm{l} / \mathrm{h}$. As a result, the velocity of the gases is $0.41 \mathrm{~m} / \mathrm{s}$. From these values the $\mathrm{O}_{2}$ molar fraction is ranged from 6 to $10 \%$. As a condition for these variations the total mass flow of the gases at the entrance was maintained constant at $3.89 \times 10^{-4} \mathrm{~kg} / \mathrm{s}$. The behavior of unburned fraction $U$ in terms of these new molar fractions is shown in Fig. 2.

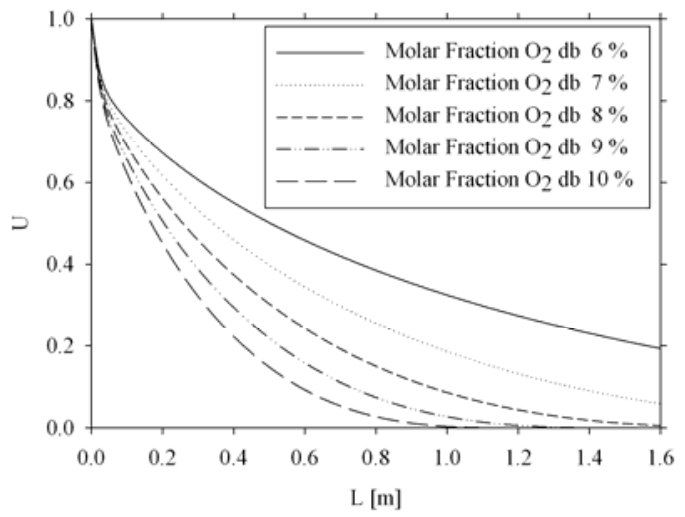

Figure 2. Behavior of unburnt fraction $U$ for different $\mathrm{O}_{2}$ mole fractions on a dry basis at the entrance of

DTF to the temperature of $1723 \mathrm{~K}$ and $\alpha=1 / 3$.

Figure 2 shows the variation of oxygen concentration directly affects reaction rates, to the point that with $8 \%$ of $\mathrm{O}_{2}$ molar fraction the unburnt fraction $U$ approaches zero at the reactor end. As the oxygen concentration increases, the reaction rate becomes increasingly intense, and this information is represented by the intensity of the decrease slope of the curves of $U$.

\section{Total flow mass:}

For this set the $\mathrm{O}_{2}$ concentration was maintained at $8 \%$ and the total flow mass was changed from 80 until $120 \%$ of the reference value. The behavior of unburnt fraction $U$ due to change the mass flow of gases is shown in Fig. 3a.

Looking at the results in Fig. $3 \mathrm{a}$ it can be seen that even increasing the mass flow, and the velocity of the gases directly, there were no major changes in the behavior of the reactor. The amount of $\mathrm{O}_{2}$ required for complete combustion does not change with increasing mass flow of gas. However, when reducing the mass flow it also affects the $\mathrm{O}_{2}$ amount, and will eventually reduce the reaction rate.
Figure $3 \mathrm{~b}$ shows the $\mathrm{O}_{2}$ mass fraction variation in the reactor, $\mathrm{y}_{\mathrm{O} 2}$, and on the particle surface, $\mathrm{y}_{\mathrm{O} 2, \mathrm{~s}}$, along the reactor. It is possible to note that although the mass fraction and the initial $\mathrm{O}_{2}$ concentration are the same for all cases, the amount of oxygen available for reaction is different for each case, changing $\mathrm{O}_{2}$ diffusion to the particle surface, and thus the reaction rate is changed. So a reduction in mass flow reduces the overall heterogeneous reaction rates even when flow velocity is reduced.
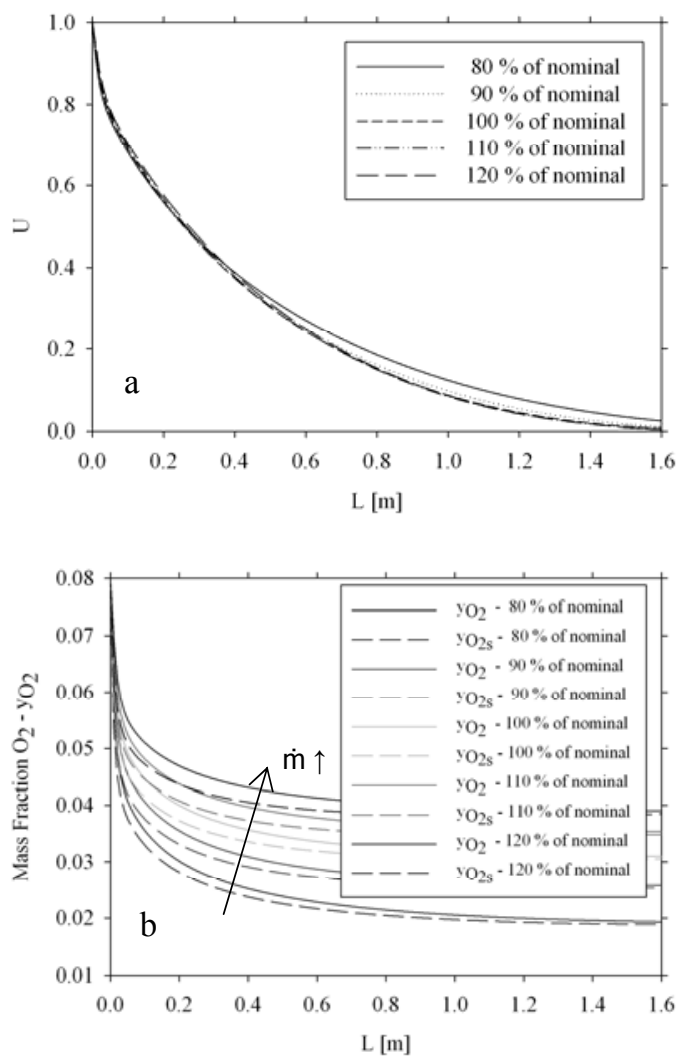

Figure 3. a) Behavior of unburnt fraction $U$ due to change the mass flow of gases at the entrance of DTF to the temperature of $1723 \mathrm{~K}$ in the system, $\alpha=1 / 3$; $\mathrm{b}$ ) Variation of the mass fraction of $\mathrm{O}_{2}, \mathrm{y}_{\mathrm{O} 2}$, and mass fraction of $\mathrm{O}_{2}$ on the particle surface, $\mathrm{y}_{\mathrm{O} 2, \mathrm{~s}}$, along the reactor for varying the mass flow of gases to a temperature of $1723 \mathrm{~K}, \alpha=1 / 3$.

Particle diameter:

The nominal particle diameter was set at $50 \mu \mathrm{m}$, and different values of particles diameter were simulated around the nominal. The feed rate was maintained at $30 \mathrm{~g} / \mathrm{h}$. The behavior of unburnt fraction $U$ as a function of variation of particle diameter is shown in Fig. 4a.

Figure $4 \mathrm{a}$ shows an expected relationship that the particle diameter has with the unburned fraction $\mathrm{U}$. As it is maintained the coal feed rate, the quantity of carbon is the same but the diameter was changed, and consequently the reaction rate is altered. As the 
diameter decreases, the rate of conversion increases, i.e., the slope of the curve $U$ becomes more pronounced. To investigate the sensitivity of the system to larger particle, bigger than $100 \mu \mathrm{m}$, particles of 100 to $500 \mu \mathrm{m}$ were then tested and are shown in Fig. $4 b$. As a result of the increased on the particle size the difficulty of conversion increases. The intense conversion rate at the entrance of the reactor can be explained by the intense mass loss of the particle due to devolatilisation process. However, the $\mathrm{O}_{2}$ diffusion is inversely proportional of the particle diameter causing a decrease in the combustion rate, showed as less intense $\mathrm{U}$ curves.
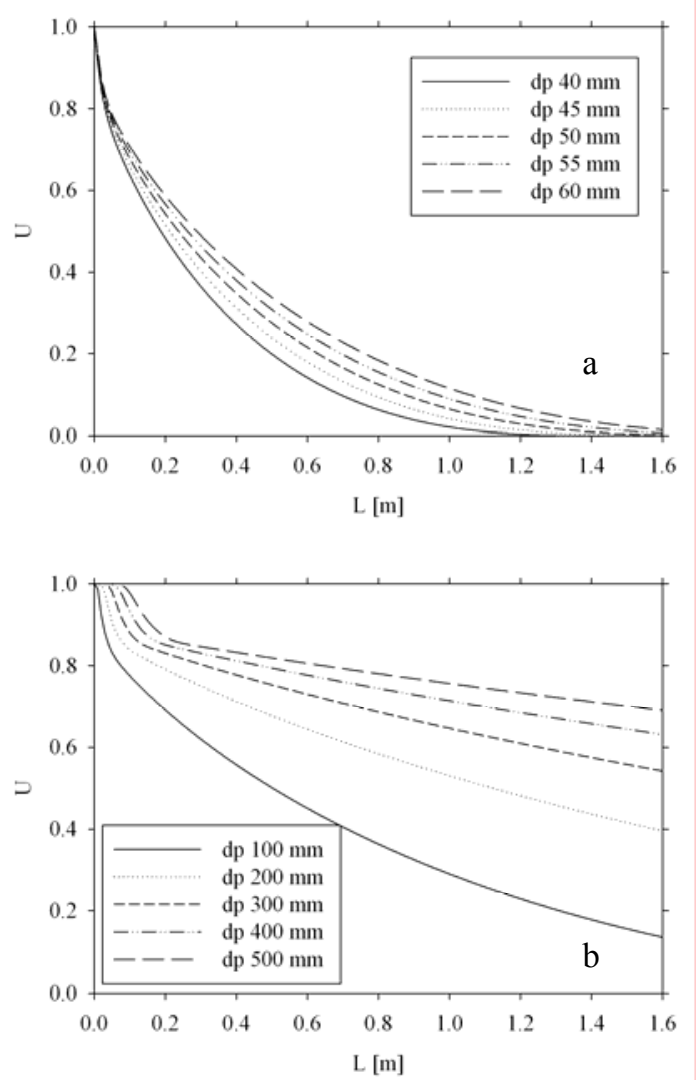

Figure 4. a) The behavior of unburnt fraction $U$ as a function of variation of small particle diameters on temperature of $1723 \mathrm{~K}, \alpha=1 / 3$; b) The behavior of unburnt fraction $U$ as a function of variation of big particle diameters on temperature of $1723 \mathrm{~K}, \alpha=1 / 3$.

\section{CONCLUSIONS}

In this work, a one-dimensional numerical model of a drop tube furnace (DTF) was developed from the literature. The results were compared with the modeling and experimental data of Ballester and Jimenez (2005). Then a sensitivity study was conducted to understand the behavior of DTF and coal burning front to change some parameters of the system.

It was used an $\alpha$ equal to $1 / 3$, which represent that all reactions occurs only on the particle surface, for a population of particles with a constant diameter of $52.2 \mu \mathrm{m}$ and the kinetic parameters obtained by reference. From these parameters, the results showed good agreement with the reference model and also the experimental values. Sensitivity analysis demonstrated the versatility of the model and consequently the experiment. Using the model presented here concurrent with experimental results outcome a detailed study of the kinetic parameters of coal combustion. The application of a numerical model to simulate the coal combustion in a DTF allowed a better understanding of each stage of this complex process. Moreover, this kind of tool has a greater versatility and ability to explore models of coal combustion than commercial software.

With the experience gained on this work it is possible to suggest further studies: add a particles size distribution model, add a model of relative velocity of the particles, compare other models of burning coal, and build a DTF based on the knowledge reported here.

\section{ACKNOWLEDGEMENTS}

The first author thanks CAPES due to the financial support by means of his Master Degree scholarship, and the second and the last author acknowledge CNPq due to financial support.

\section{REFERENCES}

Ballester, J., and Jimenez, S., 2005, Kinetic Parameters for the Oxidation of Pulverised Coal as Measured from Drop Tube Tests, Combustion and Flame, Vol. 142, pp. 210-222.

Basu, P., 2006, Combustion and Gasification in Fluidized Beds, CRC Press.

BP - British Petroleum, 2012, Statistical Review of World Energy June 2012.

CGEE 2012, Carvão Mineral Nacional Situação Atual de Dimensões de Análise, Documento Subsidiário para Construção do Roadmap Tecnológico para Produção e uso Limpo do Carvão Mineral Nacional, Encomendado pelo MCTI ao CGEE. (in Portuguese)

Coelho, P., and Costa, M., 2007, Combustão, 1ed. Portugal, Edições Orion.

EPE, 2011, Brazilian Energy Balance 2011 Year 2010, Empresa de Pesquisa Energética - Rio de Janeiro.

Glassman, I., and Yetter, R. A., 2008, Combustion, Fourth Edition, Academic Press, Massachusetts.

Poling, B. E., Prausnitz, J. M., and O’Connell, J. P., 2001, The Properties of Gases and Liquids, Mcgraw-Hill.

Smith, I. W., 1971, Kinetics of Combustion of Size-Graded Pulverized Fuels in Temperature-Range 1200-2270 Degrees K, Combustion and Flame, 
Vol. 17, No. 3, pp. 303-314.

Smith, I. W., 1971b, Kinetics of Combustion of Pulverized Semi-Anthracite in Temperature-Range 1400-2200 Degrees K, Combustion and Flame, Vol. 17, No. 3, pp. 421-428.

Smoot, L. D., and Smith, P. J., 1985, Coal combustion and gasification, Plenum Press.

Tomeczek, J., and Palugniok, H., 1996, Specific Heat Capacity and Enthalpy of coal Pyrolysis at Elevated Temperatures, Fuel, Vol. 75, No. 9, pp. 1089-1093.

Turns, S. R., 2000, An introduction to Combustion: Concepts and Applications, McGrawHill.

Ulloa, C, Borrego, A. G., Helle, S., Gordon, A. L., and Garcia, X., 2005, Char Characterization and DTF Assays as Tools to Predict Burnout of Coal Blends in Power Plants, Fuel, Vol. 84, pp. 247-257.

Williams, A., Pourkashanian, M., and Jones, J. M., 2000, The Combustion of Coal and Some other Solid Fuels, Proceedings of the Combustion Institute, Vol. 28, pp. 2141-2162. 